\title{
Glucose regulates secretion of exogenously expressed insulin from HepG2 cells in vitro and in a mouse model of diabetes mellitus in vivo
}

\author{
Y Y Liu ${ }^{1,2}$, W Jia ${ }^{2}$, I E Wanke ${ }^{2}$, D A Muruve ${ }^{2}$, H P Xiao' and N C W Wong ${ }^{2}$ \\ 'Department of Endocrinology, First Affiliated Hospital, Sun Yat-sen University, Guangzhou, Guangdong 510080, \\ People's Republic of China \\ ${ }^{2}$ Departments of Medicine and Biochemistry and Molecular Biology, Faculty of Medicine, University of Calgary, \\ Calgary, Alberta, Canada T2N 4N1
}

Correspondence should be addressed to H P Xiao or N C W Wong Email

xiaohp@mail.sysu.edu.cn or ncwwong@ucalgary.ca

\begin{abstract}
Glucose-controlled insulin secretion is a key component of its regulation. Here, we examined whether liver cell secretion of insulin derived from an engineered construct can be regulated by glucose. Adenovirus constructs were designed to express proinsulin or mature insulin containing the conditional binding domain (CBD). This motif binds GRP78 (HSPA5), an endoplasmic reticulum (ER) protein that enables the chimeric hormone to enter into and stay within the ER until glucose regulates its release from the organelle. Infected HepG2 cells expressed proinsulin mRNA and the protein containing the CBD. Immunocytochemistry studies suggested that GRP78 and proinsulin appeared together in the ER of the cell. The amount of hormone released from infected cells varied directly with the ambient concentration of glucose in the media. Glucose-regulated release of the hormone from infected cells was rapid and sustained. Removal of glucose from the cells decreased release of the hormone. In streptozotocin-induced diabetic mice, when infected with adenovirus expressing mature insulin, glucose levels declined. Our data show that glucose regulates release of exogenously expressed insulin from the ER of liver cells. This approach may be useful in devising new ways to treat diabetes mellitus.
\end{abstract}

Journal of Molecular Endocrinology (2013) 50, 337-346

\section{Introduction}

Diabetes mellitus is a terrible disease that is becoming a worldwide epidemic. The worldwide prevalence of this disease will likely reach $4.4 \%$ by 2030 (Wild et al. 2004). A primary defect in diabetes mellitus is an absent or insufficient activity of insulin, leading to type 1 or 2 diabetes respectively. Exogenously injected insulin lowers blood glucose and thus it remains a cornerstone for treating the disease (Rodbard et al. 2009, American Diabetes Association

\section{Key Words}

- Diabetes

- Non-beta cell insulin secretion

- Glucose-dependent
2011). But problems arise when the dose of insulin injected fails to match caloric intake resulting in unwanted hyper- or hypoglycemia leading to life-threatening consequences. Whereas chronic hyperglycemia underlies the long-term complications of the disease, hypoglycemia gives rise to acute events with more dire outcomes (Cryer et al. 2003, Turchin et al. 2009). Thus, treatment guidelines for diabetes mellitus include targets that define both upper and lower 
limits of glucose (Bhattacharyya et al. 2009, Rodbard et al. 2009, American Diabetes Association 2011).

Current therapies for diabetes cannot eliminate undesirable swings in glucose. Thus, interest to restore or mimic the body's ability to sense insulin action and in turn regulate levels of the hormone to avoid hyper- or hypoglycemia remains high. This issue has been addressed using islet and non-islet cells (Efrat 1998, Yoon \& Jun 2002, Olson \& Thule 2008). In non-islet cell studies, proof of concept studies, in animals, using gene transfer to produce insulin involves a glucose-sensitive promoter that controls insulin gene transcription and thus in turn the synthesis of the hormone but not its secretion (Thule et al. 2000, Chen et al. 2001, Alam \& Sollinger 2002, Hsu et al. 2008). In the absence of glucose-regulated insulin release, transcriptional control by itself might produce a lag phase in the secretory response of insulin to meals, which may lead to initial hyperglycemia followed later by hypoglycemia.

Glucose control of pancreatic insulin secretion is a key step in regulating activity of the hormone. The use of glucose to manipulate secretion of engineered insulin from a non-pancreatic cell remains a challenge. Information derived from such a system would help us understand more the role of rapidly released insulin in regulating plasma glucose in vivo. The recent use of hyaluronidase mixed with rapid acting analog insulin (lispro) in clinical trials to enable faster absorption of insulin supports the need for such knowledge (Hompesch et al. 2011, 2012). Therefore, to mimic glucose control of insulin release in vivo, especially the first phase of pancreatic insulin secretion, we expressed and stored a chimeric hormone in liver cells followed by the use of glucose to regulate secretion of insulin in vitro and in vivo.

\section{Materials and methods}

\section{Adenovirus constructs}

The conditional binding domain (CBD) is a heptapeptide (FYQLAKT) that binds glucose-regulated protein 78 (GRP78 (HSPA5)) (Shiu et al. 1977, Fourie et al. 1994, Gething 1999), an endoplasmic reticulum (ER) protein in eukaryotes. Oligonucleotides encoding CBD when placed behind the signal sequence of human preproinsulin cDNA will express a fusion hormone (Dorner et al. 1990). Mutations in preproinsulin cDNA were created using Gene Tailor (Invitrogen). Adenoviruses were constructed using the AdEasy system (Stratagene, La Jolla, CA, USA) as per instructions and amplified in HEK293 cells, purified by double $\mathrm{CsCl}$ density-gradient centrifugation, and dialyzed
(10 mmol/l Tris-Cl, PH $8.0 ; 2 \mathrm{mmol} / \mathrm{l} \mathrm{MgCl}_{2}$; and $4 \%$ sucrose $(\mathrm{w} / \mathrm{v}))$. Optical density at $260 \mathrm{~nm}$ provided particle number and expressed as optical particle units per milliliter (OPU/ml).

\section{Cell culture}

HEK293 (ATCC, Manassas, VA, USA; CRL-1573) cells were grown in DMEM, 10\% FBS (v/v), and 1\% penicillinstreptomycin (v/v) (Invitrogen). HepG2 (ATCC HB-8065) cells grown in MEM $\alpha$ with $10 \%$ FBS and $1 \%$ penicillinstreptomycin were infected with adenovirus at $70-80 \%$ confluency.

\section{Quantitative real-time and semiquantitative PCR}

RNA isolation and RT were performed using standard methodology with RNeasy Mini Kit (Qiagen), random hexamers, and M-MLV reverse transcriptase (Invitrogen). Real-time PCR primers and probes were designed using Primer3 Software (Applied Biosystems): proinsulin sense 5'-GGGGAACGAGGCTTCTTCTA-3'; probe FAM-5'-GAGGCAGAGGACCTGCAG-3'-MGB; antisense 5'-CACAATGCCACGCTTCTG-3'. $20 \times 18 S$ rRNA FAM/MGB probe (Applied Biosystems) was used as the endogenous control. Amplification was performed in MicroAmp Fast Optical 96-well reaction plates (Applied Biosystems) using the 7900HT Fast Real-Time PCR System (Applied Biosystems), and results were analyzed with SDS 2.3 and RQ Manager Software Applied Biosystems). Semiquantitative reverse transcriptase PCR were performed using an MJ Research PTC-100 thermal cycler with denaturation at $94{ }^{\circ} \mathrm{C}$, annealing at $60{ }^{\circ} \mathrm{C}$, and extension at $72{ }^{\circ} \mathrm{C}$, for a total of 30 cycles. PCR products were analyzed on $1.5 \%$ agarose gel. Primers for proinsulin sense: 5'-CCGGGATCCATTTGTGAACCAACACCTGTGC-3'; antisense: 5'-GCGGCGGCCGC CTAGTTGCAGTAGTTCTCCAG-3' . Primers for GAPDH were used as previously reported (Zerbini et al. 2003).

\section{Immunoblotting}

HepG2 cells or mouse liver lysates were extracted in buffer (50 mmol/l Tris-HCl, pH 7.4, 150 mmol/1 NaCl, 1\% NP-40 (v/v), $1 \mathrm{mmol} / \mathrm{l}$ of $\mathrm{Na}_{3} \mathrm{VO}_{4}$, phenylmethylsulfonyl fluoride, $\mathrm{NaF}$, and $10 \mu \mathrm{g} / \mathrm{ml}$ aprotinin and leupeptin) and then separated on 13\% SDS-polyacrylamide gel and transferred to PVDF membrane for western blot analysis using antiinsulin, anti-GRP78, anti-GRP94 antibodies (Santa Cruz Biotechnology), or anti- $\beta$-tubulin (Sigma) and peroxidaseconjugated secondary antibodies before visualization with the

Published by Bioscientifica Ltd. 
ECL detection system (Amersham Pharmacia). Signal intensity of the bands was normalized to the corresponding first or $\beta$-tubulin band on the same membrane.

\section{Immunoprecipitation}

Cell lysate containing $700 \mu \mathrm{g}$ total protein was diluted to a final volume of $300 \mu \mathrm{l}$ with lysis buffer. To this, $20 \mu \mathrm{l}$ protein A/G agarose beads (Santa Cruz Biotechnology) were added and the mixture was incubated for $1 \mathrm{~h}$ at $4{ }^{\circ} \mathrm{C}$ with gentle rocking. Next, the beads were pelleted and the supernatant saved to which was added $2 \mu \mathrm{g}$ anti-GRP78 or anti-insulin antibody or normal IgG (Santa Cruz Biotechnology) and $20 \mu \mathrm{l}$ agarose beads followed by incubation at $4{ }^{\circ} \mathrm{C}$ with gentle rocking overnight. The mixture was separated by centrifugation and the pellet was washed with lysis buffer before release of bound material by boiling and then SDS-polyacrylamide gel separation.

\section{Immunofluorescence}

HepG2 cells grown on coverslips or frozen mouse liver sections were fixed with $4 \%$ paraformaldehyde or methanol, permeabilized with $0.5 \%$ Triton X-100 (v/v), and incubated with anti-insulin, anti-GRP78, or anti-GRP94 antibodies (Santa Cruz Biotechnology) before exposure to Alexa Fluor-conjugated secondary antibody (Molecular Probes, Burlington, ON, Canada) and viewed using an inverted microscope controlled by NIS-Elements Imaging Software (Nikon, Melville, NY, USA).

\section{Streptozotocin-diabetic mice and virus injection}

Female Balb/CJ mice (3-6 weeks, Jackson Lab, Bar Harbor, ME, USA) were fed standard chow plus water ad libitum and diabetes was induced by daily injections of streptozotocin (STZ, $50 \mathrm{mg} / \mathrm{kg}$ ) for 5 days. Tail vein glucose was monitored using the FreeStyle Mini meter (Abbott). Diabetes was present if glucose $\geq 11.1 \mathrm{mmol} / 1$ for 3 consecutive days before injecting animals ( $n \geq 6$ /group) with AdSsCbdInsF3 $\left(0.7 \times 10^{9}-1.0 \times 10^{9} \mathrm{pfu}\right)$ or control (AdEGFP or diluent) via tail vein (Shayakhmetov et al. 2004). All procedures were approved and complied with guidelines at University of Calgary.

\section{Intraperitoneal glucose tolerance test}

Mice fasted $\geq 6 \mathrm{~h}$ were injected i.p. with $2 \mathrm{~g} / \mathrm{kg}$ glucose (Davalli et al. 1995) and glucose monitored for 15 or $30 \mathrm{~min}$ up to $120 \mathrm{~min}$.

\section{Serum assays}

Serum was separated from clotted blood collected by cardiac puncture and then stored at $<-70{ }^{\circ} \mathrm{C}$. Human insulin was assayed in serum aliquots $(25 \mu \mathrm{l})$ using the ultrasensitive human insulin ELISA (Mercodia, Uppsala, Sweden).

\section{Statistical analysis}

Analyses were performed using Student's $t$-test or oneway ANOVA and results expressed as mean values \pm s.D. (in vitro studies) or \pm s.e.M. (in vivo studies). Results were considered statistically significant at $P<0.05$.

\section{Results}

\section{CBD motif containing constructs and expression in HepG2 cells}

In order for glucose to regulate secretion of exogenously expressed (pro)insulin from HepG2 cells, we exploited features of the CBD. This heptapeptide binds GRP78, an ER protein with ATPase activity (Fourie et al. 1994). When glucose is abundant, so is ATP leading to formation of GRP78 monomers, which do not bind CBD. But when ATP is low, GRP78 becomes a dimer and it binds to CBD-proinsulin to keep this fusion protein in the ER (Dorner et al. 1990, Toledo et al. 1993). Thus, we inserted nucleotides encoding CBD between the signal peptide and proinsulin of the human preproinsulin cDNA (Fig. 1A, AdSsCbdProins) to yield chimeric CBDproinsulin. CBD-containing cDNA was placed into adenovirus vectors to yield AdSsCbdProins. The existence of CBD in the resulting mRNA was confirmed by RT-PCR assay using CBD sequence-specific primers (data not shown).

Next, adenovirus $\left(10^{8}-10^{10} \mathrm{OPU} / \mathrm{ml}\right)$ derived from the above construct was used to infect HepG2 cells for a fixed period of $24 \mathrm{~h}$. Proinsulin mRNA expression determined by RT-PCR (Fig. 1B) showed that proinsulin was expressed successfully using $10^{8} \mathrm{OPU} / \mathrm{ml}$ of virus. Although mRNA abundance appeared higher in cells infected with more $\left(10^{9}\right.$ or $\left.10^{10}\right)$ virus, cells appeared less healthy in the latter. Additionally, differing infection times (Fig. 1C) revealed proinsulin mRNA expression at $24 \mathrm{~h}$. Longer infection times of 48-72 h appeared to yield slightly higher levels of the mRNA. In subsequent studies, cells were infected with $10^{9} \mathrm{OPU} / \mathrm{ml}$ of virus for $24 \mathrm{~h}$.

Published by Bioscientifica Ltd 
A

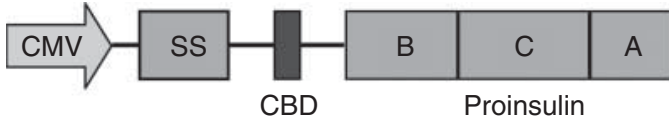

B
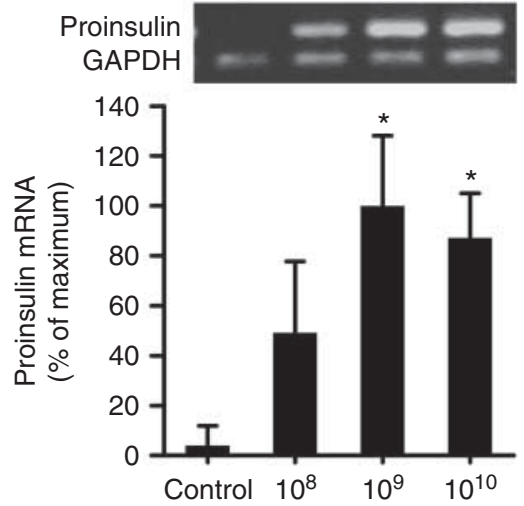

Adenovirus (OPU/ml)
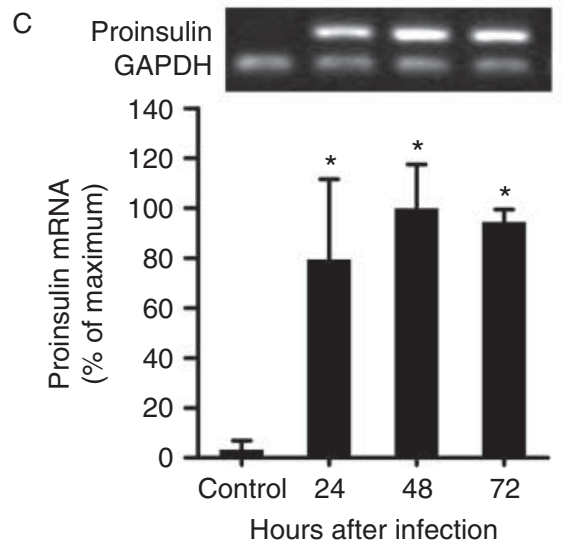

Figure 1

Expression of CBD-proinsulin in HepG2 cells. (A) Schematic illustration of the human preproinsulin CDNA-containing CBD inserted between signal sequence (SS) and proinsulin sequence. (B) mRNA expression of CBD-proinsulin in HepG2 cells infected with $10^{8}, 10^{9}$, and $10^{10} \mathrm{OPU} / \mathrm{ml}$ AdSsCbdProins adenovirus for $24 \mathrm{~h}$ (RT-PCR). Control: $10^{10} \mathrm{OPU} / \mathrm{ml}$ AdEGFP adenovirus. (C) mRNA expression of CBD-proinsulin in HepG2 cells infected with $10^{9} \mathrm{OPU} / \mathrm{ml}$ AdSsCbdProins adenovirus for 24,48 , and $72 \mathrm{~h}$ (RT-PCR). Control: $10^{9} \mathrm{OPU} / \mathrm{ml}$ AdEGFP for $72 \mathrm{~h}$. Both graphs (B and $C$ ) show densitometry analysis of data collected using semiquantitative RT-PCR expressed as a percentage of maximum signal (mean \pm s.D., $n=3$ ). $\star P<0.05$ vs control group.

\section{Glucose regulates CBD-proinsulin release from HepG2 cells}

Our construct (Fig. 1A) was not designed for glucose to regulate its expression. Thus, as expected, abundance of CBD-proinsulin mRNA in HepG2 cells infected with the AdSsCbdProins was not dependent on extracellular glucose (Fig. 2A). To examine proinsulin release, HepG2 cells infected with AdSsCbdProins were exposed to glucose from 0 to $20 \mathrm{mmol} / \mathrm{l}$ for 1 day. CBD-proinsulin in spent media was assessed using western blot analysis. Results (Fig. 2B) showed that CBD-proinsulin levels rose hand in hand with glucose concentrations such that in $0 \mathrm{mmol} / 1$ glucose CBD-proinsulin was low. Abundance of extracellular CBD-proinsulin was significantly higher in cells exposed to 2.5 vs $0 \mathrm{mmol} / \mathrm{l}$ glucose. CBD-proinsulin secretion into media continued to rise in the presence of $5-10 \mathrm{mmol} / \mathrm{l}$ followed by a plateau beyond $10-20 \mathrm{mmol} / \mathrm{l}$ glucose. These studies show the following: i) CBD-proinsulin levels in the media rise with the glucose concentration from 0 to $10 \mathrm{mmol} / \mathrm{l}$, ii) thereafter, its release plateaus in the presence of glucose $>10 \mathrm{mmol} / \mathrm{l}$, and iii) abundance of CBD-proinsulin in the media increases in response to extracellular glucose.

The preceding studies do not address CBD-proinsulin release from cells in response to fluctuating glucose concentrations. Thus, infected cells were exposed to $5 \mathrm{mmol} / \mathrm{l}$ glucose followed by replacement of media containing more or no glucose $(7.5$ or $0 \mathrm{mmol} / \mathrm{l})$ respectively every hour. Results (Fig. 2C) showed that levels of the chimeric hormone rose following exposure to $7.5 \mathrm{mmol} / 1$ glucose. By contrast, CBD-proinsulin release into the media declined but not until $2-3 \mathrm{~h}$ in the absence of glucose. These findings show that CBD-proinsulin release from cells was glucose regulated. Additionally, cellular release of CBD-proinsulin triggered by $7.5 \mathrm{mmol} / 1$ glucose appears more rapid than the decline in hormone release induced by $0 \mathrm{mmol} / \mathrm{l}$ glucose.

\section{Kinetics of CBD-proinsulin release from HepG2 cells}

The kinetics of CBD-proinsulin release was examined using infected HepG2 cells kept in $0 \mathrm{mmol} / \mathrm{l}$ glucose for $16 \mathrm{~h}$ before exposure to hyperglycemia $(15 \mathrm{mmol} / \mathrm{l})$. Spent media were collected at 10 -min intervals $\times 6$ followed by every hour extending to $5 \mathrm{~h}$ and samples were analyzed using western blot analysis (Fig. 2D). Abundance of CBD-proinsulin in media was minimal at the first 10-min point. But thereafter, abundance of the hormone rose steadily such that after $60 \mathrm{~min}$ of exposure to $15 \mathrm{mmol} / \mathrm{l}$ glucose, extracellular CBD-proinsulin was nearly sevenfold higher vs at the start. The CBD-proinsulin level peaked at $2-3 \mathrm{~h}$ of exposure to $15 \mathrm{mmol} / 1$ glucose and was sustained to $5 \mathrm{~h}$. Glucose-regulated release of CBD-proinsulin from infected cells appears quickly within 10-20 $\mathrm{min}$ and reaches a plateau beyond $60 \mathrm{~min}$ of exposure to $15 \mathrm{mmol} / \mathrm{l}$ glucose.

Published by Bioscientifica Ltd. 
A
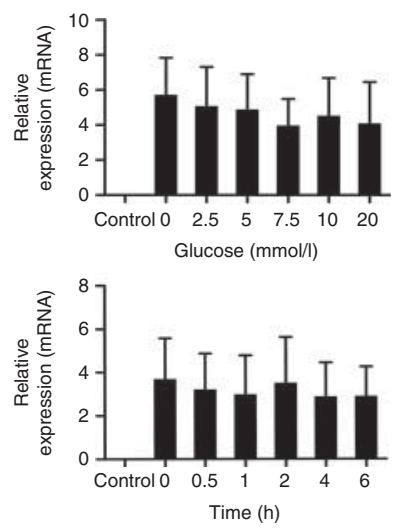

C

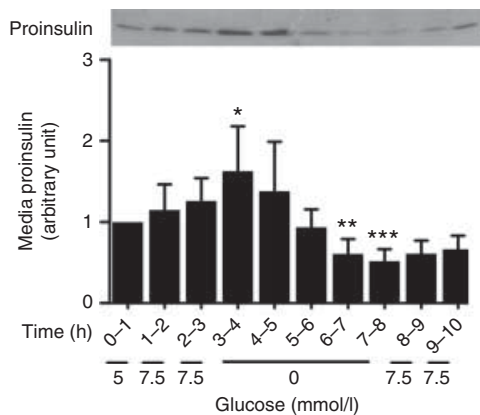

B

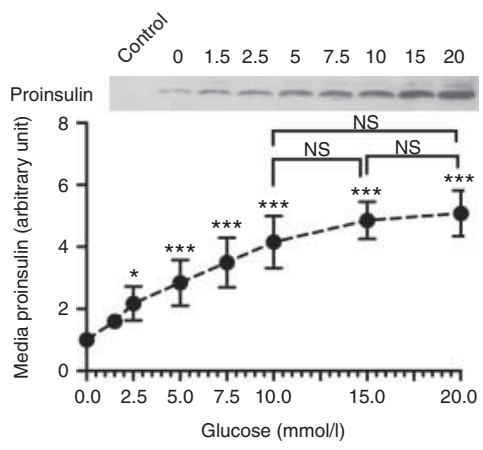

D

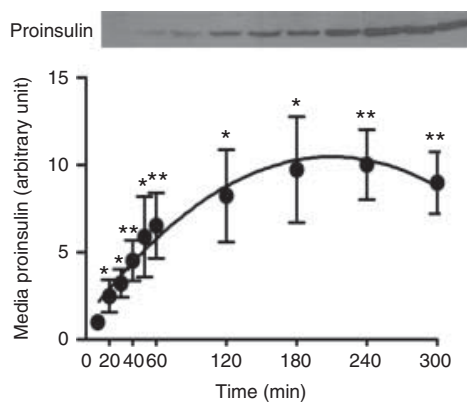

\section{Figure 2}

Glucose regulates release but not synthesis of CBD-proinsulin. (A) Real-time PCR results of CBD-proinsulin mRNA expression relative to $18 \mathrm{~S}$ in HepG2 cells infected with AdSsCbdProins under varying concentrations of glucose (top panel) or varying time of exposure to $15 \mathrm{mmol} / \mathrm{l}$ glucose (bottom panel) (mean \pm s.D., $n \geq 3$ ). (B) CBD-proinsulin secretion from HepG2 cells infected with AdSsCbdProins adenovirus detected using western blot analysis (top panel). The graph shows optical density of CBD-proinsulin signal from the western blot reflecting hormone secretion from cells treated with various concentrations of glucose (mean \pm s.D., $n=5$ ).

\section{CBD-proinsulin associated with GRP78 is retained in the ER}

The presence of the CBD motif within proinsulin should enable it to associate with GRP78. To test this hypothesis, antibodies against proinsulin and GRP78 were used in immunoprecipitation studies. Spent media and lysates from AdSsCbdProins-infected cells exposed to 0 or $7.5 \mathrm{mmol} / \mathrm{l}$ glucose for $24 \mathrm{~h}$ were studied using western blot analysis. Results (Fig. 3A) in spent media showed that CBD-proinsulin levels were higher in cells exposed to $7.5 \mathrm{mmol} / \mathrm{l}$ glucose. In lysate, the converse was seen with CBD-proinsulin (Fig. 3B, upper panel) being minimally more abundant in cells treated with 0 vs $7.5 \mathrm{mmol} / 1$ glucose. Additionally, GRP78 was also more abundant in $0 \mathrm{mmol} / \mathrm{l}$ glucose (Fig. 3B, middle panel).

Next, immunoprecipitation studies were performed by adding anti-insulin antibody to cell lysates and then
$* P<0.05, * * * P<0.001$ vs $0 \mathrm{mM}$ glucose group; NS, non-significant. (C) CBD-proinsulin secretion from infected HepG2 cells in response to fluctuating glucose level detected using western blot analysis (top panel). Graph showing relative amounts of CBD-proinsulin secreted from cells (mean \pm s.D., $n=6$ ). ${ }^{*} P<0.05, * * P<0.01, * * * P<0.001$ vs baseline level. (D) Kinetics of CBD-proinsulin release from infected HepG2 cells treated with $15 \mathrm{mmol} / \mathrm{l}$ glucose assessed using western blot analysis (top panel). Graph shows relative amounts of CBD-proinsulin secreted from cells (mean \pm s.D., $n=4$ ). ${ }^{*} P<0.05, * * P<0.01$ vs 10 -min point.

analyzing the pull down material. Results (Fig. 3C, upper panel) showed that abundance of CBD-proinsulin was higher inside cells exposed to 0 vs $7.5 \mathrm{mmol} / \mathrm{l}$ glucose. The same pull down material also contained GRP78 (Fig. 3C, lower panel). We speculate that the lower level of CBD-proinsulin in $7.5 \mathrm{vs}$ $0 \mathrm{mmol} / \mathrm{l}$ glucose in Fig. 3C, when compared to Fig. 3B, is likely due to the added immunoprecipitation step in pulling down less CBD-proinsulin before western blot analysis. The converse experiment using the anti-GRP78 antibody added to lysates pulled down material that contained GRP78 (Fig. 3D, lower panel) as well as proinsulin (Fig. 3D, upper panel). The findings using both antibodies are consistent with the idea that CBD-proinsulin and GRP78 exist as a complex inside the infected cells.

To further examine whether CBD-proinsulin and GRP78 may appear together, AdSsCbdProins-infected

Published by Bioscientifica Ltd 
A
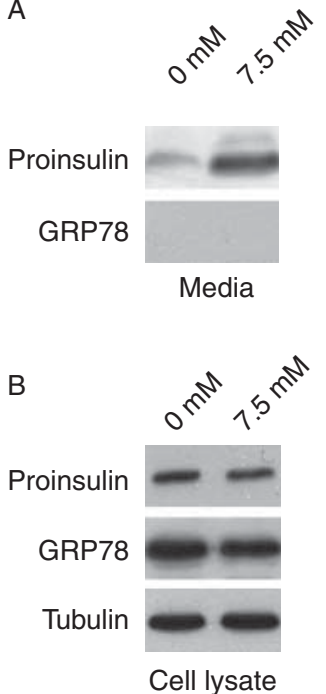

C

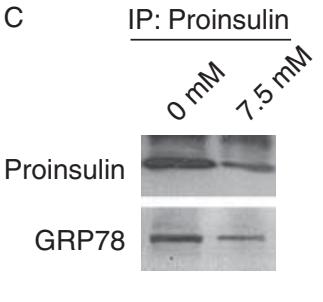

D

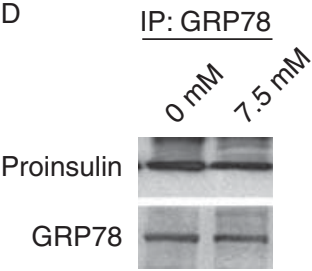

E

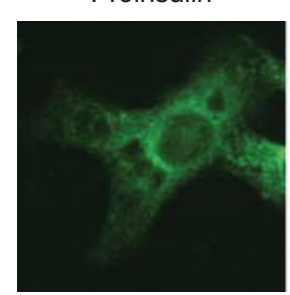

F

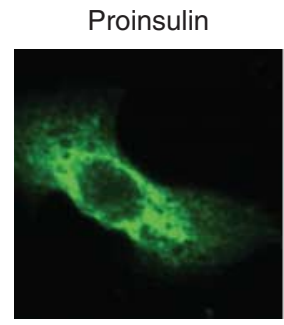

GRP78

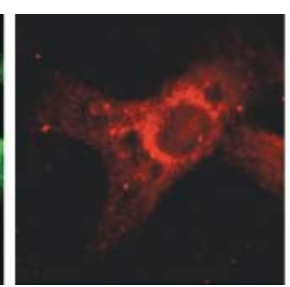

GRP94

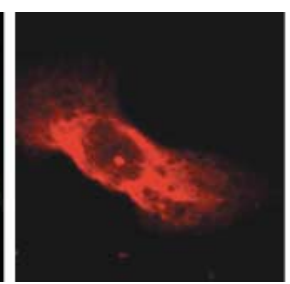

Merge
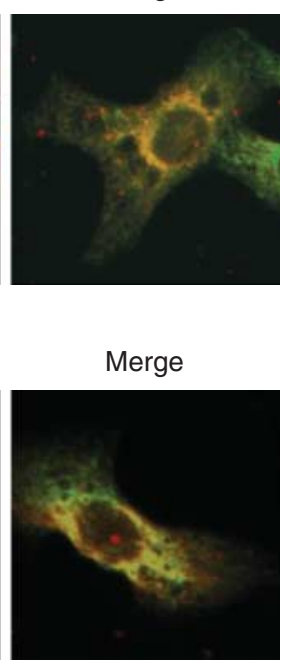

\section{Figure 3}

CBD-proinsulin associated with GRP78 is retained in the ER. (A) Western blot analysis of CBD-proinsulin secreted from HepG2 cells infected with AdSsCbdProins adenovirus in response to 0 or $7.5 \mathrm{mmol} / /$ glucose. (B) Lysate content of CBD-proinsulin and GRP78 in infected HepG2 cells treated with 0 or $7.5 \mathrm{mmol} / \mathrm{l}$ glucose. (C and D) Immunoprecipitation (IP) of lysate from infected HepG2 cells using anti-insulin (C) or -GRP78 (D) antibodies,

HepG2 cells were exposed to media without glucose for $3 \mathrm{~h}$. These cells were exposed to an antibody against proinsulin or GRP78 followed by confocal microscopy. Results (Fig. 3E) in green and red reflected staining by proinsulin or GRP78 respectively. When the two separate pictures were layered on top of each other, the merged image turned yellow suggesting co-localization of the two proteins. To gather further evidence that CBD-proinsulin was located in the ER, we stained infected cells with an antibody against GRP94, another protein that resides within the ER. An image (Fig. 3F) of the overlay stained for proinsulin (green) or GRP94 (red) showed predominant yellow, again suggesting co-localization of these two proteins. These data support the idea that both CBD-proinsulin and GRP78 appear together and likely in the ER of infected cells.

\section{Diabetic mice infected with a construct designed to express mature insulin}

While CBD-proinsulin was useful for the in vitro studies, in a mouse model of diabetes mellitus, mature insulin should be more efficient in lowering glucose. In order for CBD-proinsulin to be converted to mature insulin by liver cells, the chimeric hormone must be cleaved between CBD/B-chain, B-chain/C-peptide, and C-peptide/A-chain. followed by western blot analysis of pull down material for proinsulin and GRP78. ( $E$ and F) Infected HepG2 cells were exposed to antibodies against proinsulin, GRP78, or GRP94 and then examined using confocal microscopy. Images were taken separately for proinsulin and GRP78 (E) or proinsulin and GRP94 (F) and finally merged together.

Previous studies showed that furin cut sites may be useful for this conversion (Nishigori et al. 1996). Thus, furin cut sites were inserted at strategic locations to yield AdSsCbdInsF3. The fusion hormone arising from this construct is recognized by the furin protease family found in liver and their activity on this substrate should yield mature insulin (Denault \& Leduc 1996).

Balb/CJ mice made diabetic using STZ were then infected with the AdSsCbdInsF3 virus. Diabetic mice injected with either AdEGFP or diluent served as controls. Insulin expression in mouse liver was assessed using RT-PCR and western blot analysis against insulin antibody. As expected, results showed the presence of both proinsulin mRNA (Fig. 4A) and protein (Fig. 4B) in liver from diabetic mice injected with AdSsCbdInsF3 but not from control mice. Additionally, immunohistology studies showed that liver from AdSsCbdInsF3-injected mouse stained positive for insulin expression (Fig. 4C).

Next, we measured the glucose levels in these mice. In diabetic mice, 2 days following infection with AdSsCbdInsF3, the morning glucose level was lower compared with that in diabetic controls. Furthermore, the glucose levels in diabetic mice carrying AdScCbdInsF3 (Fig. 4E, black triangle) continued to drop toward euglycemia from days 3 to 7 following viral infection vs diabetic control mice (black dots) in which glucose levels

Published by Bioscientifica Ltd 


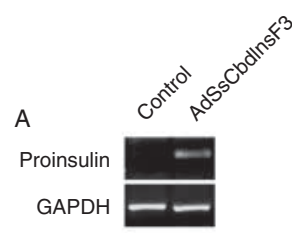

B Proinsulin Tubulin C
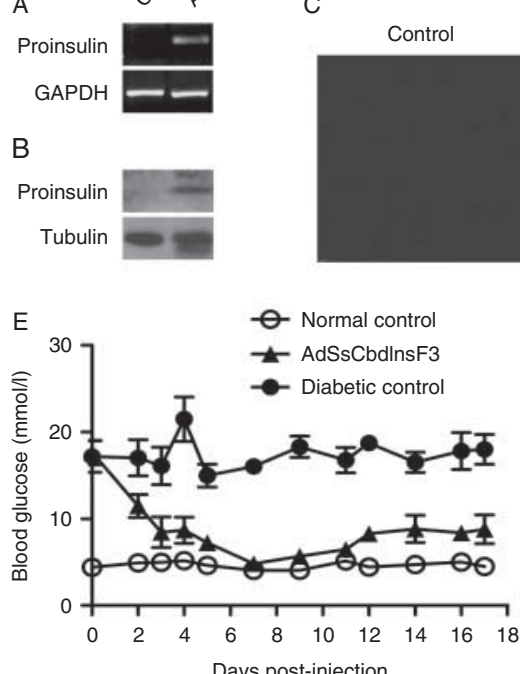

Days post-injection
AdSsCbdlnsF3
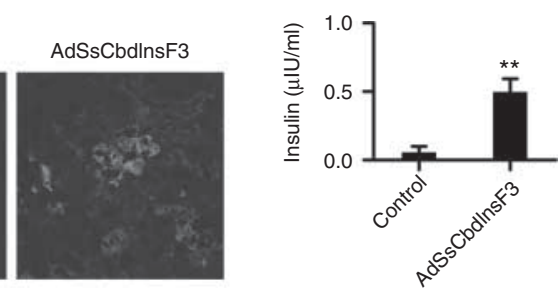

$\mathrm{F}$

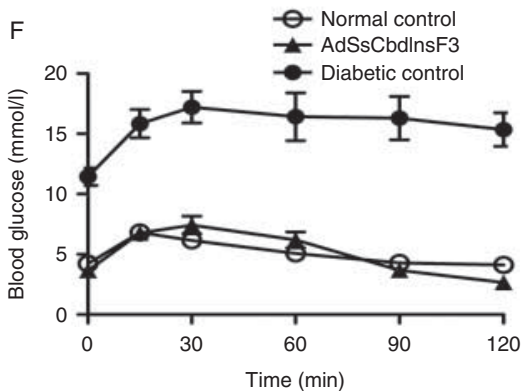

\section{Figure 4}

AdSsCbdlnsF3 adenovirus lowers glucose levels in diabetic mice. (A) RT-PCR results of proinsulin mRNA expression relative to GAPDH in liver tissue of Balb/CJ mice infected with AdScCbdInsF3. (B) Western blot analysis of proinsulin expression relative to $\beta$-tubulin in liver tissue of $\mathrm{Balb} / \mathrm{CJ}$ mice infected with AdScCbdInsF3. (C) Frozen mice liver section was stained for insulin and then examined using confocal microscopy. (D) Serum human insulin levels of Balb/CJ mice infected with AdSsCbdlnsF3 in comparison to

remained high. In AdSsCbdInsF3-infected mice beyond 7 days to the end of the study, glucose levels remained much lower than those in diabetic control mice. Additionally, human insulin was assayed in mice from each group, which showed that diabetic mice infected with AdSsCbdInsF3 had significantly higher levels of human insulin in comparison to the control mice (Fig. 4D). The presence of human insulin correlated with the lower blood glucose levels in the infected animals.

The AdSsCbdInsF3 construct was created to yield mature insulin, and it should be more efficient in lowering glucose compared with the prohormone. Thus, glucose levels in diabetic mice injected with AdSsCbdProins or AdSsCbdInsF3 were compared. In mice equipped to express mature insulin, the glucose levels were lower than those producing the prohormone. Also, human insulin levels measured using ELISA assay in mice injected with AdSsCbdInsF3 were threefold higher compared with those injected with AdSsCbdProins (data not shown). Proinsulin is known to be roughly $5-10 \%$ as potent as mature insulin (Shaw \& Chance 1968, Lazarus et al. 1970).

Next, an intraperitoneal glucose tolerance test (IPGTT) was performed in these mice following a $\geq 6$-h control mice (mean \pm s.E.M., $n \geq 6$ ). $* * P<0.01$ vs control group. (E) Morning blood glucose was measured after STZ injection and on indicated day after AdSsCbdInsF3 adenovirus injection. (F) IPGTT was performed after virus injection. White circles, normal control mice; black triangles, mice injected with AdSsCbdInsF3 adenovirus; black dots, mice injected with AdEGFP adenovirus or diluent without virus (mean \pm S.E.M., $n \geq 6$ ).

fast. Blood glucose levels were measured after i.p. injection of glucose. Results (Fig. 4F) showed that mice carrying AdSsCbdInsF3 did not have hyperglycemia at the start and glucose remained lower vs diabetic control mice throughout the study. Glucose levels in the diabetic mice carrying AdSsCbdInsF3 mimicked those in non-diabetic mice and not in diabetic control mice subjected to the same IPGTT. These observations suggest that in this STZ-induced diabetic Balb/CJ mouse model, infection with AdSsCbdInsF3 lowers glucose vs that of diabetic control animals in the morning or response to IPGTT.

\section{Discussion}

Insulin therapy is a mainstay in the treatment of patients with diabetes mellitus (Rodbard et al. 2009, American Diabetes Association 2011). But the consequences of its actions on glucose are not perfect because it is difficult for patients to predict the exact dose of hormone to inject so that it matches the body's needs. If a mismatch occurs, it ends in hyper- or, worst, hypoglycemia. To address this issue, we want to study new ways that enable glucose to regulate insulin release from non-islet cells. This interest

Published by Bioscientifica Ltd. 
led us to create a model that attempts to mimic the initial aspect of pancreatic insulin release. Our data show that the release of insulin expressed in liver cells can be regulated by glucose.

Our data show that HepG2 cells infected with the AdSsCbdProins expressed proinsulin mRNA (Fig. 1B and C) and the hormone. The amount of proinsulin released from infected cells varied directly with the ambient concentration of glucose in the media (Fig. 2B). The glucose-regulated release of the hormone from infected cells was rapid and sustained (Fig. 2D). Removal of glucose from the cells decreased release of the hormone (Fig. 2C). Immunoprecipitation (Fig. 3C and D) and immunocytochemistry (Fig. 3E and F) data suggested that GRP78 and proinsulin appeared together in the ER of the infected cell. In STZ-induced diabetic mice, when infected with adenovirus (AdSsCbdInsF3) that expressed mature insulin, glucose levels declined (Fig. 4E and F). Together, our observations in vitro and in vivo show that the constructs can direct the synthesis of insulin in liver cells but more importantly glucose regulates its activity in this animal model.

The potential importance of our data may become clearer when viewed in the light of studies by others addressing a similar issue. Previous attempts to mimic pancreatic function in regulating insulin have used nonislet cells, including hepatocytes, to express and secrete insulin (Lu et al. 1998, Chen et al. 2005, Wilson et al. 2005, Hsu et al. 2008). The general approach involved use of a glucose-responsive promoter or motif to control insulin gene transcription (Thule et al. 2000, Chen et al. 2001, Alam \& Sollinger 2002, Hsu et al. 2008). An inherent feature of glucose-regulated insulin expression, as a control point, is that it gives rise to a lag phase during which the gene is transcribed and then translated. These time-dependent processes result in a delay that precedes the onset of action from the newly synthesized insulin. This delay may lead to an initial hyperglycemic response following exposure to glucose and then possibly hypoglycemia when insulin synthesis surpasses the needs (Lu et al. 1998, Olson et al. 2003).

Physiological release of insulin is biphasic and begins with an initial surge followed by a gentle sustained flow of the hormone (Porte \& Pupo 1969). While the transcriptional approach in non-islet cells might reproduce the second phase of insulin release, it does not replicate the first phase. For example, in studies using an adenovirus carrying a glucose-regulated insulin gene, glucose levels remained high in most animals immediately after the meal (Thule \& Liu 2000, Olson et al. 2003). Additionally, the combined use of adeno-associated virus and adenovirus to deliver a glucose-responsive, liver-specific promoter is reported to lower glucose below $200 \mathrm{mg} / \mathrm{dl}$ in diabetic mice (Kozlowski et al. 2007). Despite the sustained hormone release arising from glucose-regulated insulin gene transcription, when tested in animal models of diabetes mellitus, glucose levels did not mimic physiological patterns (Thule \& Liu 2000, Riu et al. 2002, Olson et al. 2003, Kozlowski et al. 2007).

Why transcriptional models do not mimic pancreatic control of the hormone may, in part, be due to the inability of this approach to control insulin secretion. Studies targeting this specific step have used non-pancreatic endocrine cells in which glucose regulates release of non-insulin hormones. These cells were engineered to synthesize large quantities of insulin. For example, studies of $\mathrm{K}$ cells in mice expressing human insulin driven by the rat GIP promoter were promising (Cheung et al. 2000). But unfortunately, $\mathrm{K}$ cells are present in crypts of the gut and thus they are very difficult to use for viral transduction due to accessibility. Additionally, intestinal epithelial cells undergo very rapid turnover, so repeated delivery of the transgenic gene into these progenitor cells is needed. Together, these features of $\mathrm{K}$ cells added to their inherent function of releasing non-insulin hormones affected by glucose (i.e. GIP) represent a barrier for their use in clinical applications. A central issue in using either a glucoseresponsive promoter or non-pancreatic cell approaches to mimic pancreatic insulin release is the inability to replicate a bolus secretion of the hormone. The lack of this insulin surge following glucose stimulation is important in physiological control of the hormone.

Studies to address this issue have been attempted (Rivera et al. 2000, Tian et al. 2008) by controlling insulin secretion at the level of the ER using drug-induced protein disaggregation. These studies demonstrated that protein secretion could be controlled at the posttranslational step and the ER as a useful storage site. However, the use of pharmacological agents and not glucose to regulate insulin release is fraught with difficulties such as adjustment of drug dosage to address hyper- or hypoglycemia. Thus, these models still do not replicate physiological insulin release.

A potential issue of storing chimeric proinsulin in the ER is that it might induce stress leading to apoptosis. But we found no evidence of this problem on cell viability or differences in biomarkers of stress and apoptosis, GRP78, GRP94, and caspase-3 and -7 in hormone-expressing cells vs control (data not shown). Furthermore, studies summarized here and those of others showed that use of ER as

Published by Bioscientifica Ltd. 
a storage site for exogenously expressed protein did not lead to cell toxicity or activation of markers denoting ER stress (Rivera et al. 2000, Tian et al. 2008).

In summary, the work of others suggests that replicating pancreatic insulin release in non-islet cells remains an elusive goal. Toward this objective, we have devised a way that enables glucose to regulate release of exogenously expressed insulin from the ER of liver cells. Both glucose regulation and ER storage of proinsulin are possible by fusing the CBD motif to the hormone (Fourie et al. 1994). In vitro, glucose controls the release of chimeric proinsulin from HepG2 cells. In vivo, the adenovirus that expresses mature insulin lowers glucose vs diabetic controls. While our data have many limitations, it is a step in replicating the initial phase of pancreatic insulin release.

\section{Declaration of interest}

The authors declare that there is no conflict of interest that could be perceived as prejudicing the impartiality of the research reported.

\section{Funding}

This work was supported in part by a Graduate Student Fellowship from the China Scholarship Council (to $Y$ Y L).

\section{Author contribution statement}

All authors contributed to acquisition, analysis, and interpretation of data; revised the manuscript; and approved the final version. I E W had a significant role in developing the idea for the project.

\section{Acknowledgements}

The authors would like to acknowledge Dr Li Ren (University of Calgary) for his mentoring of $Y Y L$ and previous contributions to the project. They also thank Sharon Clark and Zhong Qiao Shi (University of Calgary) for providing technical support to the study.

\section{References}

Alam T \& Sollinger HW 2002 Glucose-regulated insulin production in hepatocytes. Transplantation 74 1781-1787. (doi:10.1097/00007890200212270-00024)

American Diabetes Association 2011 Standards of medical care in diabetes - 2011. Diabetes Care 34 (Suppl 1) S11-S61. (doi:10.2337/ dc11-S011)

Bhattacharyya OK, Estey EA \& Cheng AY 2009 Update on the Canadian Diabetes Association 2008 clinical practice guidelines. Canadian Family Physician Médecin de Famille Canadien 55 39-43.

Chen R, Meseck ML \& Woo SL 2001 Auto-regulated hepatic insulin gene expression in type 1 diabetic rats. Molecular Therapy 3 584-590. (doi:10.1006/mthe.2001.0299)

Chen NK, Sivalingam J, Tan SY \& Kon OL 2005 Plasmid-electroporated primary hepatocytes acquire quasi-physiological secretion of human insulin and restore euglycemia in diabetic mice. Gene Therapy 12 655-667. (doi:10.1038/sj.gt.3302446)

Cheung AT, Dayanandan B, Lewis JT, Korbutt GS, Rajotte RV, Bryer-Ash M, Boylan MO, Wolfe MM \& Kieffer TJ 2000 Glucose-dependent insulin release from genetically engineered K cells. Science 290 1959-1962. (doi:10.1126/science.290.5498.1959)

Cryer PE, Davis SN \& Shamoon H 2003 Hypoglycemia in diabetes. Diabetes Care 26 1902-1912. (doi:10.2337/diacare.26.6.1902)

Davalli AM, Ogawa Y, Scaglia L, Wu YJ, Hollister J, Bonner-Weir S \& Weir GC 1995 Function, mass, and replication of porcine and rat islets transplanted into diabetic nude mice. Diabetes 44 104-111. (doi:10.2337/diabetes.44.1.104)

Denault JB \& Leduc R 1996 Furin/PACE/SPC1: a convertase involved in exocytic and endocytic processing of precursor proteins. FEBS Letters 379 113-116. (doi:10.1016/0014-5793(95)01487-X)

Dorner AJ, Wasley LC \& Kaufman RJ 1990 Protein dissociation from GRP78 and secretion are blocked by depletion of cellular ATP levels. PNAS $\mathbf{8 7}$ 7429-7432. (doi:10.1073/pnas.87.19.7429)

Efrat S 1998 Prospects for gene therapy of insulin-dependent diabetes mellitus. Diabetologia 41 1401-1409. (doi:10.1007/s001250051085)

Fourie AM, Sambrook JF \& Gething MJ 1994 Common and divergent peptide binding specificities of hsp70 molecular chaperones. Journal of Biological Chemistry 269 30470-30478.

Gething MJ 1999 Role and regulation of the ER chaperone BiP. Seminars in Cell \& Developmental Biology 10 465-472. (doi:10.1006/scdb.1999.0318)

Hompesch M, Muchmore DB, Morrow L \& Vaughn DE 2011 Accelerated insulin pharmacokinetics and improved postprandial glycemic control in patients with type 1 diabetes after coadministration of prandial insulins with hyaluronidase. Diabetes Care 34 666-668. (doi:10.2337/dc10-1892)

Hompesch M, Muchmore DB, Morrow L, Ludington E \& Vaughn DE 2012 Improved postprandial glycemic control in patients with type 2 diabetes from subcutaneous injection of insulin lispro with hyaluronidase. Diabetes Technology \& Therapeutics 14 218-224. (doi:10.1089/ dia.2011.0117)

Hsu PY, Kotin RM \& Yang YW 2008 Glucose- and metabolically regulated hepatic insulin gene therapy for diabetes. Pharmacological Research 25 1460-1468. (doi:10.1007/s11095-008-9539-x)

Kozlowski M, Olson DE, Rubin J, Lyszkowicz D, Campbell A \& Thule PM 2007 Adeno-associated viral delivery of a metabolically regulated insulin transgene to hepatocytes. Molecular and Cellular Endocrinology 273 6-15. (doi:10.1016/j.mce.2007.04.011)

Lazarus NR, Penhos JC, Tanese T, Michaels L, Gutman R \& Recant L 1970 Studies on the biological activity of porcine proinsulin. Journal of Clinical Investigation 49 487-496. (doi:10.1172/JCI106258)

Lu D, Tamemoto H, Shibata H, Saito I \& Takeuchi T 1998 Regulatable production of insulin from primary-cultured hepatocytes: insulin production is up-regulated by glucagon and cAMP and down-regulated by insulin. Gene Therapy 5 888-895. (doi:10.1038/sj.gt.3300677)

Nishigori T, Yanagita M \& Takeuchi T 1996 Proinsulin cleaved by furin is processed to chromatographically mature insulin by carboxypeptidases in nonneuroendocrine cells. Peptides 17 789-796. (doi:10.1016/01969781(96)00077-0)

Olson DE \& Thule PM 2008 Gene transfer to induce insulin production for the treatment of diabetes mellitus. Expert Opinion on Drug Delivery 5 967-977. (doi:10.1517/17425247.5.9.967)

Olson DE, Paveglio SA, Huey PU, Porter MH \& Thule PM 2003 Glucoseresponsive hepatic insulin gene therapy of spontaneously diabetic BB/Wor rats. Human Gene Therapy 14 1401-1413. (doi:10.1089/ 104303403769211628)

Porte D Jr \& Pupo AA 1969 Insulin responses to glucose: evidence for a two pool system in man. Journal of Clinical Investigation 48 2309-2319. (doi:10.1172/JCI106197)

Riu E, Mas A, Ferre T, Pujol A, Gros L, Otaegui P, Montoliu L \& Bosch F 2002 Counteraction of type 1 diabetic alterations by engineering skeletal muscle to produce insulin: insights from transgenic mice. Diabetes $\mathbf{5 1}$ 704-711. (doi:10.2337/diabetes.51.3.704) 
Rivera VM, Wang X, Wardwell S, Courage NL, Volchuk A, Keenan T, Holt DA, Gilman M, Orci L, Cerasoli F Jr et al. 2000 Regulation of protein secretion through controlled aggregation in the endoplasmic reticulum. Science 287 826-830. (doi:10.1126/science.287.5454.826)

Rodbard HW, Jellinger PS, Davidson JA, Einhorn D, Garber AJ, Grunberger G, Handelsman Y, Horton ES, Lebovitz H, Levy P et al. 2009 Statement by an American Association of Clinical Endocrinologists/American College of Endocrinology consensus panel on type 2 diabetes mellitus: an algorithm for glycemic control. Endocrine Practice 15 540-559.

Shaw WN \& Chance RE 1968 Effect of porcine proinsulin in vitro on adipose tissue and diaphragm of the normal rat. Diabetes 17 737-745.

Shayakhmetov DM, Li ZY, Ni S \& Lieber A 2004 Analysis of adenovirus sequestration in the liver, transduction of hepatic cells, and innate toxicity after injection of fiber-modified vectors. Journal of Virology $\mathbf{7 8}$ 5368-5381. (doi:10.1128/JVI.78.10.5368-5381.2004)

Shiu RP, Pouyssegur J \& Pastan I 1977 Glucose depletion accounts for the induction of two transformation-sensitive membrane proteinsin Rous sarcoma virus-transformed chick embryo fibroblasts. PNAS $\mathbf{7 4}$ 3840-3844. (doi:10.1073/pnas.74.9.3840)

Thule PM \& Liu JM 2000 Regulated hepatic insulin gene therapy of STZdiabetic rats. Gene Therapy 7 1744-1752. (doi:10.1038/sj.gt.3301297)

Thule PM, Liu J \& Phillips LS 2000 Glucose regulated production of human insulin in rat hepatocytes. Gene Therapy 7 205-214. (doi:10.1038/sj.gt. 3301076)
Tian J, Lei P, Laychock SG \& Andreadis ST 2008 Regulated insulin delivery from human epidermal cells reverses hyperglycemia. Molecular Therapy 16 1146-1153. (doi:10.1038/mt.2008.79)

Toledo H, Carlino A, Vidal V, Redfield B, Nettleton MY, Kochan JP, Brot N \& Weissbach H 1993 Dissociation of glucose-regulated protein Grp78 and Grp78-IgE Fc complexes by ATP. PNAS 90 2505-2508. (doi:10.1073/ pnas.90.6.2505)

Turchin A, Matheny ME, Shubina M, Scanlon JV, Greenwood B \& Pendergrass ML 2009 Hypoglycemia and clinical outcomes in patients with diabetes hospitalized in the general ward. Diabetes Care $\mathbf{3 2}$ 1153-1157. (doi:10.2337/dc08-2127)

Wild S, Roglic G, Green A, Sicree R \& King H 2004 Global prevalence of diabetes: estimates for the year 2000 and projections for 2030. Diabetes Care 27 1047-1053. (doi:10.2337/diacare.27.5.1047)

Wilson MO, Scougall KT, Ratanamart J, McIntyre EA \& Shaw JA 2005 Tetracycline-regulated secretion of human (pro)insulin following plasmid-mediated transfection of human muscle. Journal of Molecular Endocrinology 34 391-403. (doi:10.1677/jme.1.01646)

Yoon JW \& Jun HS 2002 Recent advances in insulin gene therapy for type 1 diabetes. Trends in Molecular Medicine 8 62-68. (doi:10.1016/S14714914(02)02279-7)

Zerbini LF, Wang Y, Cho JY \& Libermann TA 2003 Constitutive activation of nuclear factor $\kappa \mathrm{B}$ p50/p65 and Fra- 1 and JunD is essential for deregulated interleukin 6 expression in prostate cancer. Cancer Research $632206-2215$.

Received in final form 4 February 2013

Accepted 7 February 2013

Accepted Preprint published online 7 February 2013
C 2013 Society for Endocrinology Printed in Great Britain
Published by Bioscientifica Ltd. 